\title{
Conversations with Architects in the Age of Celebrity
}

\author{
BELOGOLOVSKY, Vladimir
}

Berlín, DOM Publishers, 2015

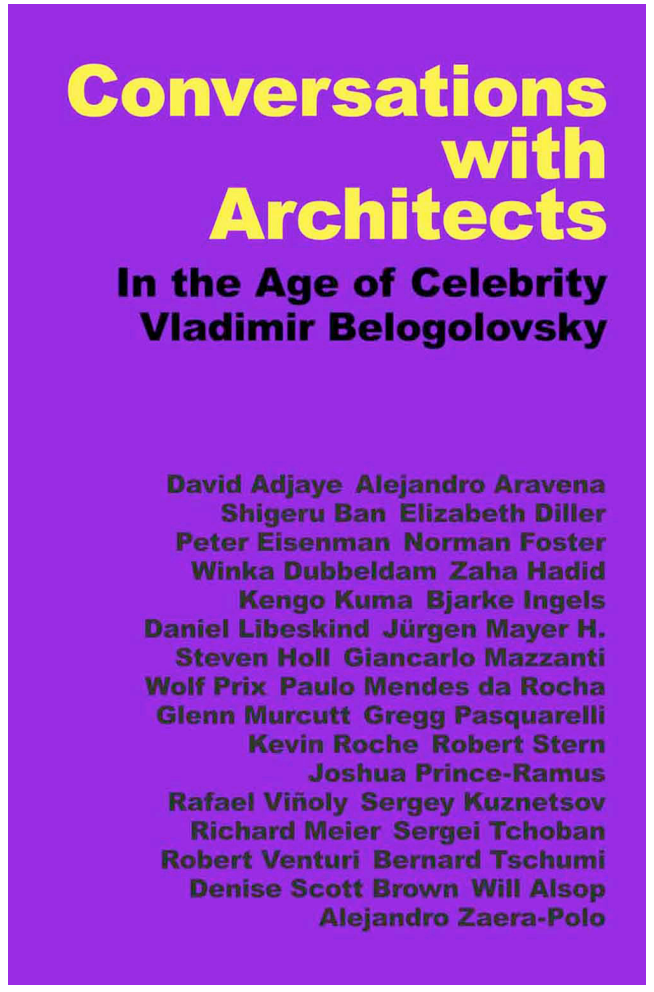

Un credo a revisar

Las manifestaciones de repulsa hacia el concepto de star-architect por parte de aquellas figuras etiquetadas bajo esa categoría han ido manifestándose con una creciente virulencia a lo largo de los últimos años. Desde las esporádicas proclamas lamentando los precedentes excesos que convergieron en poderosa voz alta en la declaración lanzada por Paolo Baratta en su presentación de la Bienal de Arquitectura de Venecia en 2012 -en la que se exculpaba a los arquitectos de los delirios icónicos cometidos y se les victimizaba, culpando a una sociedad caprichosa y hambrienta de edificios insólitos de haberles forzado a ello- ${ }^{1}$, al grosero gesto de Frank Gehry respondiendo a un periodista que le inquirió en torno a la arquitectura como espectáculo², a la reciente furibunda declaración de Patrik Schumacher tildando de simplista construcción discursiva el concepto de edificio icono ${ }^{3}$, pasando por las puntuales negativas (en forma de distanciamiento o de evasivas) a aceptar el término y sus implicaciones que pueden reconocerse en entrevistas a figuras protagonistas del ámbito arquitectónico, tanto en medios generales como especializados.

Posiblemente sea necesario advertir cómo en ese lapso que media entre 2009 y 2014/2015 se han podido constatar diferentes formas de posicionamiento respecto a ese rechazo. Estas se manifestaron inicialmente desde el súbito giro hacia una aparente concienciación sobre las problemáticas causadas por la recesión económica, así como la intención de romper con las estridencias icónicas al uso y el occidentocentrismo hegemónico en el panorama arquitectónico, patentes en acontecimientos como la exposición Small Scale, Big Change: New Architectures of Social Engagement ${ }^{4}$, el premio Pritzker concedido al arquitecto chino Wang Shu en 2012 (interpretable como una respetuosa reverencia de Occidente a la pujanza de China dentro del planisferio global) y al japonés Shigeru Ban en 2014 (destacando su contribución al desarrollo de arquitecturas para situaciones de emergencia) o el León de Oro con que se reconoció al proyecto Torre David en Caracas de Urban Think Tank y Justin McGuirk precisamente en la Bienal de 2012 (una decisión que no estaría exenta de controversia) $)^{5}$ Impostadas coartadas de salvación y redención, estas posiciones y discursos han ido paulatinamente delatando la persistencia del mismo sustrato ideológico, que cree en la absolutista hegemonía del arquitecto, y que ahora se reafirman con la redoblada agresividad que transmiten esas airadas reacciones antes citadas y que, cabe deducir, son reflejo del descubrimiento de nichos de alto poder económico que pueden constituirse como nuevos clientes de ese modelo arquitectónico cuyo valor se sustenta, a partes iguales, en el prestigio del aura de su autoría y en la auda- 
cia de su espectacularidad formal y tecnológica. El escrito de Schumacher es, en este sentido, fundamental por cuanto recoge, con una visceralidad que se impone sobre la construcción racional mesurada de sus argumentos, los fundamentos de esa defensa enconada de la idea de edificio icono (y del arquitecto que lo concibe) como vía esencial para una evolución del lenguaje arquitectónico. Otro aspecto crucial de este texto es la acusación que vierte sobre la crítica por haber diseminado una noción simplificada y banal del concepto de icono, haciendo de él una mera etiqueta mediática que convierte a los edificios encuadrables en esta categoría y a sus autores en fácil blanco de ataques (tanto por parte de críticos como de otros arquitectos envidiosos). Schumacher, sumándose y articulando con mayor energía declaraciones formuladas en el tiempo reciente sobre el innecesario papel de la crítica ${ }^{6}$ y negándole despreciativamente una capacidad analítica real, conmina a esta a convertirse en una actividad dependiente y cómplice de las ideas y acciones de la élite arquitectónica, destinada exclusivamente a ensalzar y jamás a cuestionar.

Ante este contexto, la aparición de un libro en cuyo título se vinculan los términos «arquitecto» $y$ «era de la celebridad» suscita inevitablemente un profundo interés. Máxime cuando el volumen compila una extensa serie de entrevistas a arquitectos pertenecientes de uno u otro modo al rango de arquitecto-estrella desde esa acepción adoptada en la cultura general, o bien desde el prestigio destacado que posee entre la profesión. El libro se toma con la expectativa de conocer de primera mano las reflexiones en torno a la noción de celebridad contemporánea y sus consecuencias, una información que sería sumamente valiosa para contribuir a la comprensión e interpretación crítica de este específico momento de incertidumbres y contradicciones en la arquitectura.

La importancia de la celebridad como una potencia fundamental de nuestro tiempo es incuestionable, aun en la evidente paradoja que presenta el dotar de trascendencia a un fenómeno cuya savia vital es precisamente la insustancialidad y la banalidad. La celebridad está ligada indisolublemente hoy a las dinámicas del neoliberalismo. La conversión del arquitecto en celebridad a través de la calculada promoción de su imagen, de la construcción de un personaje fácilmente identificable, asociado a unos clichés creativos (y temperamentales) concretos que le proporcionaban ras- gos de diferenciación, de superior individualidad, es la base desde la que se cimenta el sobrevalor de aquellos edificios portadores de su concreto nombre, atrayendo a potenciales clientes de considerable poder, copando espacio protagónico en medios de comunicación y generando así un ciclo de retroalimentación que engrosaba el tamaño del aura y deseo hacia su arquitectura. Pese a la afirmación de Schumacher en su furioso manifiesto, la crítica sí jugó un obedientísimo papel, decisivo en la consagración de estas figuras y sus obras: acató el poder de estas celebridades, sustituyendo el análisis de sus proyectos por cautivados y sublimadores discursos sobre esos egos y contribuyendo así a mantener en movimiento esa retroalimentación. Una actitud que es la que claramente se reconoce en Vladimir Belogolovsky, autor de este libro.

Desde el prólogo, Belogolovosky hace manifiesta su aceptación entusiasta del poder de la arquitectura icónica y sus artífices, de las transformaciones hacia las que la arquitectura se vea abocada por el efecto y sinergias por la conversión de la figura del arquitecto y los edificios estrella en fenómenos de consumo. En lugar de plantear un examen de los motivos de este fenómeno, Belogolovosky justifica con una excesivamente rápida y superficial argumentación el hecho de que el afán de distinguirse, a despecho de la pertinencia pragmática del edificio, ha constituido un rasgo intrínseco del arquitecto a lo largo de la historia (p. 9). No es tampoco en absoluto satisfactoria como argumentación la referencia que hace a la primera aparición del término y su subsecuente establecimiento en el vocabulario arquitectónico: «El término star-architect aparece por primera vez en la década de 1940. Según el Oxford English Dictionary fue una estrella de cine que diseñó una casa. A fines de los años 80 los arquitectos comenzaron a usar el término para referirse a las celebridades arquitectónicas pero fue a comienzos de la década de 2000 cuando los medios difundieron el uso del término» (p. 13). Habría sido deseable, tanto para el lector afín a esta perspectiva positiva sobre el poder carismático del arquitecto como para aquel discrepante con ella, disponer de una exposición más minuciosa y ponderada acerca del desarrollo cultural del concepto de celebridad ${ }^{7}$ y su específica manifestación dentro del ámbito actual de la arquitectura, habida cuenta de que no se trata de un factor meramente caprichoso o anecdótico, sino un potente justificador de procedimientos y temas de debate. 
Otro posible punto de desacuerdo con el planteamiento presentado por Belogolovsky en su prólogo es ubicar en diciembre de 2002, en el marco del evento de presentación de los proyectos escogidos para la reconstrucción del World Trade Center en Nueva York, y en el que él se encontraba presente, el punto desencadenante del fenómeno de la conversión de los arquitectos en estrellas, ignorando por algún motivo la relevancia del efecto Guggenheim a fines de la década de los 90. Es una decisión que atribuye una cierta dimensión personal al emprendimiento de este libro, pero que le permite asimismo ligar su proyecto a la toma de actitud respecto a la arquitectura icónica que planteó el fallecido crítico Herbert Muschamp en un artículo para el periódico New York Times, en fechas previas al anuncio de resolución de este concurso.

En dicho artículo, y constatando el creciente interés entre el público general por la arquitectura (patente tanto en la edición de coffee-table books, como por la aparición de arquitectos en programas televisivos como The Oprah Winfrey Show o The Simpsons), Muschamp apelaba a promover una arquitectura de cierta sofisticación pero capaz de suscitar una sensación de deleite que fuera «intensificada al desafiar el temor instintivo a lo desconocido» (p. 14). Valga la proclamación del Guggenheim «como reencarnación de Marilyn Monroe» como ejemplo del efectismo completamente alejado de la sustancia académica, desde la que tradicionalmente se había enfocado la descripción y valoración de obras arquitectónicas, que Muschamp introdujo en sus artículos. En el elaborado con motivo de la inminente resolución del concurso para el World Trade Center, Muschamp apeló a los arquitectos a que "volvieran a hacer del skyline de Manhattan el más impresionante del mundo» (p. 16). Belogolovsky aplaude la audaz originalidad que implicaba esta actitud y que usa de alguna manera como aval para su enfático entusiasmo y fascinación respecto a la arquitectura icónica del autor. Sin embargo, una vez más, la argumentación resulta excesivamente rauda y superficial. El autor no ahonda en los motivos que le llevan a apoyar y compartir este posicionamiento, pareciendo considerar explicación suficiente el fervor fascinado que un edificio espectacular y la exaltación de la visión creativa de determinados arquitectos puede provocar. Plantea así un criterio de acción que, desde este prólogo y a lo largo del libro, va manifestándose más fruto de una cautivada obediencia a un discurso de po- der y veneración a este, que consecuencia de una reflexión independiente a través de la que quedara expresada razonadamente al lector el motivo de la identificación intelectual con este. Deslizará en las entrevistas referencias a citas que han acabado deviniendo petulantes o huecos eslóganes de impacto, reiterando en particular la pronunciada por Philip Johnson («La arquitectura puede despertar la sorpresa, proporcionar placer, alegrar o conmover hasta las lágrimas; y el modo en que consiga esto es irrelevante»), sin exigirse efectuar a estas una segunda lectura o revisión que delate su contenido o su vacío.

Cabe señalar como uno de los principales puntos positivos del libro el ofrecer como prolegómeno a la serie de entrevistas sendas conversaciones con Charles Jencks (2007) y Kenneth Frampton (2009), con opiniones discrepantes respecto al fenómeno de la arquitectura estrella y la iconicidad. Jencks sitúa algo después de 2002 la fecha de la eclosión de la arquitectura estrella y apunta como antecedentes a considerar la cultura de la celebridad de los 60 y el estallido de arquitectura icónica en la década de los 70 en la Unión Soviética (p. 26). Augura la permanencia del modelo icónico y, aunque reivindicando la figura de la estrella, apela a los arquitectos a que asuman con responsabilidad su derecho a la libertad creativa así como a acatar la necesidad de aceptar y debatir públicamente los problemas de este modelo (p. 32). Frampton se muestra por su parte radicalmente detractor de la star-architecture, critica su exceso, acusa a algunos de ellos de ser «edificios totalmente faltos de ética, esencialmente groseros y bastante decepcionantes» (p. 46) y de no poseer más valor que el de ser meras imágenes atractivas (p. 54). Menciona las maquinarias publicitarias que operan tras muchas de las figuras mediáticas y recuerda que la arquitectura puede brindar placer y bienestar sin necesidad de ser impresionante (p. 57).

Los dos extremos del debate, del dilema entre ese entusiasmo aparentemente optimista y ligado a un progreso tecnológico que hay en la celebración de la arquitectura estrella y sus artífices (entendidos por ello como «idealistas»), representado por Jencks, y ese otro parecer hostil a esta (y que tiende a ser tachado de reaccionario por sus oponentes) que representa Frampton, se mantienen polarizados. Belogolovsky deja escapar aquí la oportunidad de plantear diálogos que hagan de estas entrevistas documentos que sirvan 
como posibilidades de tender puentes hacia un debate. Una omisión que es aún más crucial por cuanto el libro está compuesto por treinta entrevistas realizadas entre diciembre de 2002 y abril de 2014, y que resultan más bien cuestionarios individuales sobre el específico perfil y trabajo de cada uno de los arquitectos.

Es obligatorio señalar en este punto que estas entrevistas fueron realizadas sin la perspectiva de que fueran finalmente recogidas en un único volumen (algunas de ellas fueron publicadas previamente en revistas profesionales), algo que hasta cierto punto podría explicar el motivo de la clara falta de cohesión temática subyacente, la falta de la presencia del tema de la celebridad y la iconocidad en las preguntas formuladas a los arquitectos y que podría ser el motivo que atraería a un lector hacia esta publicación. Sin embargo, el propio Belogolovsky da a entender que el fundamento de la celebridad del arquitecto es su motivación principal a la hora de acometer estas entrevistas, y lo hace desde una complacencia rayana en la adoración: patente no solo desde elogios superlativos a la manera muschampiana, sino también en pasajes como la descripción de una lamentable escena protagonizada por Zaha Hadid y un matrimonio que deseaba encargarle un proyecto, sin querer ver cómo esta es ilustrativa de la prepotencia caprichosa del arquitecto y el servilismo estúpido del cliente que acata el maltrato y desaire (pp. 70-71). U otras del tipo: «Gehy insistía en preguntarme por qué yo quería entrevistarlo, diciéndome medio en broma que no tenía nada nuevo que decirme. Me di cuenta entonces de que solo quería hablar con él porque es el arquitecto más famoso del mundo. Tiene razón, pensé: ¿qué va a poder decirme de nuevo? Es el arquitecto en activo cuyo trabajo requiere de menos explicaciones. ¿Cómo puede explicarse el arte? Él es el artista definitivo del hacer arquitectónico» (p. 72); «Recuerdo sentirme cautivado por el discurso de Calatrava hablando poética y metafóricamente en la apertura de su exposición de 2005...» (p. 74); destacar a Rem Koolhaas como una referencia para los arquitectos jóvenes por el motivo de que desean ser «tan exitosos como él» (p. 81), o conformarse con lacónicas imprecisiones como «la arquitectura es mi vida», pronunciada por Shigeru Ban (p. 167).

Una veneración que alcanza el paroxismo en una afirmación como esta, en la que se delata el peligro de esta idolatría en la que el valor de la impresión capaz de produ- cir el edificio se antepone absolutamente a cualquier otra consideración de adecuado rigor constructivo y funcional (¿equiparando edificio correcto a arquitectura mediocre?): «No importa los pleitos contra los star-architects, puesto que muchos de sus clientes constatan ya bien adelantado el proceso que sus extraordinarios edificios no solo conllevan pagar un precio alto sino también el elevado riesgo de que no funcionen como es debido. Sin embargo, esas creaciones prometen captar la atención del público y si ese es el propósito del cliente, el resto no debería importar. Si la prioridad principal del cliente es una cubierta asequible y que no tenga filtraciones, entonces tal vez contratar a un arquitecto estrella no es la mejor decisión de partida» (pp. 74-75).

Estos elementos indican claramente cómo Belogolovksy sí ha estado atento a las cuestiones de la celebridad y lo icónico, y han sido el trasfondo que ha inducido estas entrevistas, pero elige no formular ni directa ni indirectamente preguntas sobre ellas para indagar en las opiniones personales que sobre ellas pudieran tener estos protagonistas. Sirva como ejemplo la entrevista a Peter Eisenman (pp. 206-225), con ausencia de cualquier pregunta en torno a las problemáticas que afectaban a la construcción de la Ciudad de la Cultura en Santiago de Compostela ya en 2009 (fecha de uno de los dos encuentros entre autor y arquitecto), para examinar protectoramente dicho proyecto desde su estricta dimensión conceptual, usando el diálogo para ensalzarlo como un proyecto «más sublime que be\|l». Tampoco en aquellas entrevistas efectuadas dentro del contexto de la crisis económica se detecta una reacción por su parte para inquirir al respecto del sentido del poder de los arquitectos y la arquitectura icónicos, averiguar los posibles modos en que ese estado afecta a la definición y acciones de la star-architecture o siquiera tratar de examinar si hubiera vínculos entre conceptos neoliberales y esta arquitectura de la celebridad y el exceso. Belogolovsky preserva a cada uno de los entrevistados en un territorio confortable para reafirmarlos en sus propios clichés, y son escasas las excepciones en las que alguno de ellos, como Paulo Mendes da Rocha (pp. 358-373), sale voluntariamente de este para revelar sin ambages desacuerdos 0 algún aspecto que pone en entredicho algún elemento de las dinámicas actuales de la arquitectura. Valga destacar la interesante comparación de actitudes que plantean la 


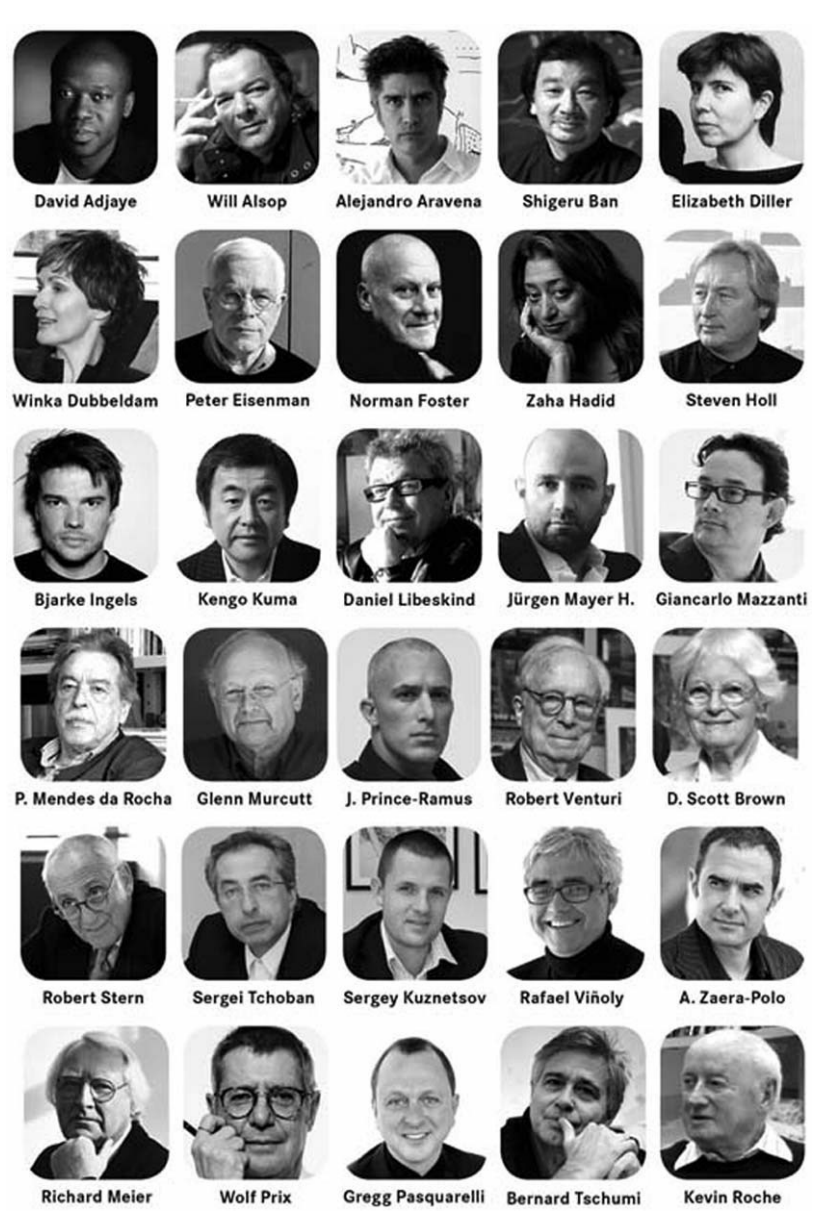

entrevista a Mendes da Rocha, insistiendo en que la arquitectura no son inspiraciones personales sino un análisis racional de historia y realidad, y la realizada a Robert Venturi y Denise Scott Brown (pp. 510-529), donde estos últimos hacen de su rechazo a los actuales gestos estridentes de afirmación individualista y de autor en la arquitectura una forma de legitimar la suya propia, un narcisismo que parece hacerles incapaces de ver que, antes que las actitudes de los egos, es más importante tasar la posible gravedad de las dinámicas de vanidad y banalidad en la relación de la arquitectura con la sociedad.

Acata sin cuestionamientos las nuevas tendencias que van introduciéndose en el discurso hegemónico y a sus representantes emblemáticos, que pasan a incorporarse a este repertorio de celebridades del medio arquitectónico: la arquitectura social en Latinoamérica (Aravena, Mazzan- ti), las nuevas jóvenes figuras emergentes (Ingels)... y que siguen consolidando ese sistema jerárquico basado en la espectacularidad y el carisma que Belogolovsky -aunando el concepto de Muschamp y la referida cita de Johnsonconsidera incuestionablemente necesario y saludable: «Los arquitectos estrella garantizan una saludable diversidad y, además de sus identidades estilísticas, instigan el desarrollo de tecnologías innovadoras y sofisticación. Son nuestros catalizadores -aunque triunfen o fracasen de las maneras más espectaculares-. [...] Centran nuestra atención y traen acentos al entorno construido que, de otro modo, sería un fondo homogéneo y anónimo para nuestras vidas. [...] Involucran al público general en el discurso arquitectónico global e incrementan su conciencia acerca del valor del buen diseño. [...] Lo que debería ser la principal preocupación de nuestros arquitectos líderes es dedicar sus talentos creativos para dotar a la arquitectura de la mayor calidad, originalidad imaginativa y conmover las emociones de las personas» (p. 84).

El libro se cierra con una página en la que aparece una selección de recientes portadas de revista, tanto especializadas en arquitectura como de llamadas glossy magazines, que reflejan el encumbramiento del rostro de determinados arquitectos, que vuelve innecesaria la imagen de su arquitectura. También incluye una selección de frases lapidarias de algunos de los star-architects del momento que no han sido entrevistados en el libro, dejando así confirmada la importancia del ícono y el eslogan como efectivas herramientas de sustentación de la figura célebre en la arquitectura de hoy, mezcla entre autoridad intelectual-creativa y mito pop.

Los reproches que esta reseña efectúa no deben sin embargo disuadir de la lectura de este libro por cuanto, como ya se ha apuntado, es necesario que tanto partidarios como cuestionadores del star-system arquitectónico profundicen en sus respectivas argumentaciones. Es opinión de quien esto suscribe que el discurso a favor de este descansa enteramente en argumentaciones de índole más emocional que racional; que reaccionan desde una exasperación que invalida cualquier objetividad que va incluso más allá de considerar irrelevante el fracaso de un proyecto-espectáculo, pues llega al extremo de negar las circunstancias que obligarían a determinadas obras a hacerse cargo de responsabilidades éticas, por lo que es 
urgente lograr establecer puntos donde debatir rigurosamente y superando el enfrentamiento. Está en juego la recuperación de una credibilidad para la arquitectura (tanto entre la sociedad como entre la misma profesión) que ha sido gravemente mermada por los excesos y caprichos de estos últimos tiempos. Sirvan los cuestionamientos aquí presentados como ruegos de respuestas más sólidas e intelectualmente responsables a ese credo laudatorio a la hegemonía de determinada élite.

\section{Alicia Guerrero Yeste \\ Crítica de arquitectura}

\section{Notas}

1 Paolo Baratta, «The exhibition of resonances», 2012. http://www.labiennale.org/en/architecture/archive/13th-exhibition/baratta/ (Fecha de consulta: 28-042015).

2 Como información de la noticia y la imagen del gesto de Gehry, véase por ejemplo Jesús Ruiz Mantilla, «El arquitecto Frank Gehry dedica una peineta a las críticas a su obra», El País, 23 octubre 2014. http://cultura.elpais.com/cultura/2014/10/23/actualidad/1414089327_576638.html (Fecha de consulta: 28-042015).

3 Patrik Schumacher publicó esta declaración en su muro de Facebook el 10 de abril de 2015. https://www.facebook.com/patrik.schumacher.10/ posts/10205380818112860?fref=nf\&pnref=story.

4 Exposición comisariada por Andres Lepik y que se presentó en el MoMA de Nueva York entre el 3 de octubre de 2010 y el 3 de enero de 2011.

5 «Una respuesta a la polémica de Torre David / Gran Horizonte», Comunicado de prensa emitido por Urban Think Tank, 1 de octubre de 2012. http://u-tt. arch.ethz.ch/wp-content/uploads/2012/10/121001_Torre_Release_es.pdf (Fecha de consulta: 28-04-2015).

6 Véanse los artículos «En estado crítico», «La melancolía mató al crítico» y «Criticofobia» en Fredy Massad, La viga en el ojo. Escritos a tiempo, Madrid, Ediciones Asimétricas, 2015.

7 Para una interesante lectura introductoria al tema consultar Fred Inglis, A Short History of Celebrity, Londres, Princeton University Press, 2010. 